\title{
KAJIAN TEGANGAN REGANGAN DAN KUAT TEKAN BETON HVFA MEMADAT SENDIRI TERHADAP BETON NORMAL
}

\author{
Syifa Rahma Alisiyah ${ }^{1)}$, Agus Setiya Budi' ${ }^{2}$, Endah Safitri ${ }^{3)}$ \\ 1) Mahasiswa Fakultas Teknik, Prodi Teknik Sipil, Universitas Sebelas Maret \\ 2) Pengajar Fakultas Teknik, Prodi Teknik Sipil, Universitas Sebelas Maret \\ 3) Pengajar Fakultas Teknik, Prodi Teknik Sipil, Universitas Sebelas Maret \\ Jl. Ir. Sutami 36A, Kentingan Surakarta 57126; Telp. (0271) 634524, Fax 662118 \\ Email : syifaalisiyah@gmail.com
}

\begin{abstract}
The utilization of fly ash from the residual of coal combustion can be used in concrete innovation because it has a small size as cement substituent and filler with a proportion of $\geq 50 \%$. Fly ash contains high silica $\left(\mathrm{SiO}_{2}\right)$ functions as a pozzolan which can bind the results of the residual cement bydration reaction with water in the form of crystals of $\mathrm{Ca}(\mathrm{OH})_{2}$ to CSH gel which can increase the strength of concrete, this innovation is known as High Volume Fly ash (HVFA) concrete. The use of other added materials in the form of superplasticizer so that the concrete can compact by itself aims to overcome the problem of forming cavities in reinforced concrete, this innovation is known as Self Compacting Concrete (SCC). If the innovations are combined can be called HVFA-SCC concrete. This study examines stress-strain and compressive strength of HVF $A$ SCC concrete against normal concrete with 50\% fly ash content at 28 days. The samples of concrete are made in the form of cylinders measuring $150 \mathrm{~mm} \times 300 \mathrm{~mm}$ as much 5 samples. HVFA-SCC concrete were characteristics by 3 methods: flow table test, L-box test, and V-funnel test. The result of the test showed that maximum stress between HVFA-SCC concrete and normal concrete achieved when the strain value 0.005 0.006. The compressive strength value of HVFA-SCC concrete is greater than normal concrete, it can be concluded that the addition of fly ash can increase the strength of concrete.
\end{abstract}

Keyword : compressive strength, fly ash, HVFA-SCC

\begin{abstract}
Abstrak
Pemanfaatan limbah fly ash dari sisa pembakaran batu bara dapat digunakan dalam inovasi beton karena ukurannya yang kecil sebagai substitusi semen dan filler dengan proporsi $\geq 50 \%$. Fly ash mengandung silika $\left(\mathrm{SiO}_{2}\right)$ tinggi yang berfungsi sebagai pozolan yang dapat mengikat hasil sisa reaksi hidrasi semen dengan air berupa kristal $\mathrm{Ca}(\mathrm{OH})_{2}$ menjadi gel CSH yang dapat menambah kekuatan beton, inovasi tersebut dikenal sebagai beton High Volume Fly ash (HVFA). Penggunanaan bahan tambah lain berupa superplasticizer agar beton dapat memadat sendiri bertujuan untuk mengatasi permasalahan terbentuknya rongga pada beton bertulang, inovasi tersebut dikenal sebagai beton Self Compacting Concrete (SCC). Apabila inovasi tersebut dikombinasikan dapat disebut sebagai beton HVFA-SCC. Penelitian ini mengkaji tegangan-regangan dan kuat tekan beton HVFA-SCC terhadap beton normal dengan kadar fly ash 50\% berumur 28 hari. Sampel beton yang dibuat berupa silinder berukuran $150 \mathrm{~mm}$ x $300 \mathrm{~mm}$ sebanyak 5 buah. Pengujian beton HVFA-SCC dilakukan dengan 3 metode yaitu : flow table test, L-box test, dan V-funnel test. Hasil pengujian menunjukkan bahwa tegangan maksimum antara beton HVFA-SCC dengan beton normal dicapai pada regangan tekan 0,005-0,006. Nilai kuat tekan beton HVFA-SCC lebih besar dari beton normal, hal tersebut dapat disimpulkan bahwa penambahan fly ash dapat meningkatkan kekuatan beton.
\end{abstract}

Kata Kunci : kuat tekan, fly ash, HVFA-SCC

\section{PENDAHULUAN}

Beton merupakan bahan bangunan yang terbuat dari agregat dan pengikat berupa semen yang nantinya dapat mengeras seperti batu. Penelitian mengenai beton mengalami perkembangan seiring berkembangnya ilmu pengetahuan dan teknologi, salah satunya inovasi mengenai beton memadat mandiri atau bisa disebut Self Compacting Concrete (SCC). Inovasi ini ditemukan karena beton konvensional dianggap kurang efisien sebab membutuhkan perhatian khusus pada saat penuangan, pemompaan, dan pemadatan dengan batang besi serta pengaturan di cetakan yang beresiko pada saat pengerjaannya. Beton Self Compacting Concrete (SCC) adalah beton yang mampu mengalir sendiri dan dapat dicetak pada bekisting tanpa alat pemadat karena dapat menyebar secara merata di ruang bekisting dan bisa mengalami pemerataan permukaannya sendiri dengan mengandalkan berat gravitasi campuran dan kekentalan beton. Zat kimia berupa superplasticizer digunakan pada penelitian ini sebagai bahan tambah yang diberikan pada campuran beton dengan kadar tertentu agar pencampuran air dan komponen solid terjadi secara efektif untuk memperoleh campuran beton dengan kualitas beton segar yang memadai (workable).

Bahan pengikat yang ada pada campuran beton yaitu semen, merupakan salah satu pemicu terjadinya Global Warming. Produksi semen menciptakan emisi gas $\mathrm{CO}_{2}$ yang cukup signifikan. Salah satu cara untuk menangtasi emisi gas $\mathrm{CO}_{2}$ akibat penggunaan semen pada campuran beton dapat menggunakan fly ash yang merupakan limbah dimanfaatkan sebagai bahan pengganti. Penggunaan kadar fly ash yang tinggi pada pembuatan beton yang bisa disebut High Volume Fy ash (HVFA). Jika mengacu pada latar belakang tersebut, maka dalam penelitian ini akan dikaji untuk mengetahui seberapa besar tegangan dan regangan beton High Volume Fly ash Self Compacting Concrete (HVFA-SCC) menggunakan kadar fly ash 50\% dari berat semen dan kemudian akan dibandingkan dengan beton normal. Umur beton yang akan diuji adalah 28 hari. 


\section{LANDASAN TEORI}

\section{Beton High Volume Fly ash (HVFA)}

Beton HVFA adalah beton dengan bahan campuran yang menggunakan fly ash sebagai subtituen semen dengan proporsi lebih dari 50\% total kebutuhan semen. Penambahan fly ash dapat meningkatkan workability, flowability, pumpability, compacbility, mengurangi panas hidrasi dan meningkatkan ketahanan terhadap serangan sulfat, alkalisilica reactivity (ASR)(Solis et al., 2010).

\section{Beton Self Compacting Concrete (SCC)}

Beton Self Compacting Concrete (SCC) adalah beton yang mampu mengalir karena berat dan melewati tulangan tanpa diperlukan alat penggetar, yang paling membedakan beton Self Compacting Concrete (SCC) dari beton konvensional adalah tingakat workability dan flowability yang tinggi. Beton Self Compacting Concrete (SCC) bersifat kohesif dan dapat dikerjakan tanpa terjadi bleeding maupun segregasi. Untuk mencapai pada kualitas beton Self Compacting Concrete (SCC) tersebut diperlukan adanya superplastisizer. Cara kerja superplasticizer adalah dengan menyebarkan partikel semen menjadi merata dan memisahkan menjadi partikel-partikel yang halus sehingga reaksi pembentukan C-S-H (tobermorite) akan lebih merata. Karena penambahan superplasticizer tersebut beton Self Compacting Concrete (SCC) walaupun memiliki sifat yang encer tetapi tidak perlu melakukan penambahan faktor air semen, karena semakin banyak air akan menurunkan kuat tekan beton itu sendiri.

\section{Tegangan Beton}

Tegangan $(\sigma)$ adalah gaya persatuan luas penampang benda, dengan rumus sebagai berikut.

$$
\sigma=\frac{F}{A}
$$

Dengan :

$\begin{array}{lll}\sigma & =\text { Tegangan } & (\mathrm{MPa}) \\ \mathrm{F} & =\text { Gaya } & (\mathrm{N}) \\ \mathrm{A} & =\text { Luas Permukaan Penampang } & \left(\mathrm{mm}^{2}\right)\end{array}$

\section{Regangan Beton}

Regangan adalah perubahan relatif ukuran atau bentuk benda yang mengalami tegangan, dengan rumus sebagai berikut.

$$
\varepsilon=\frac{\Delta l}{l_{0}}
$$

Dengan :

$$
\begin{array}{ll}
\varepsilon & =\text { Regangan } \\
\Delta l & =\text { Selisih panjang awal dan panjang akhir }(\mathrm{mm}) \\
l_{0} & =\text { Panjang awal }(\mathrm{mm})
\end{array}
$$

\section{METODE PENELITIAN}

Metode penelitian yang digunakan oleh peneliti adalah metode eksperimental yang dilakukan di Laboratorium Bahan dan Laboratorium Struktur Teknik Sipil Universitas Sebelas Maret serta Laboratorium Material Teknik Mesin Universitas Sebelas Maret. Benda uji yang dibuat dalam penelitian ini berupa beton HVFA-SCC dan beton normal berbentuk silinder diameter $15 \mathrm{~cm}$ dan tinggi $30 \mathrm{~cm}$ sebanyak 5 sampel, kandugan fly ash 50\% untuk beton HVFA-SCC, dan dilakukan capping menggunakan belerang pada benda uji. Pengujian yang dilakukan adalah uji kuat desak menggunakan alat UTM (Universal Testing Machine), kemudian data yang dihasilkan akan diolah menggunakan Microsoft Excel.

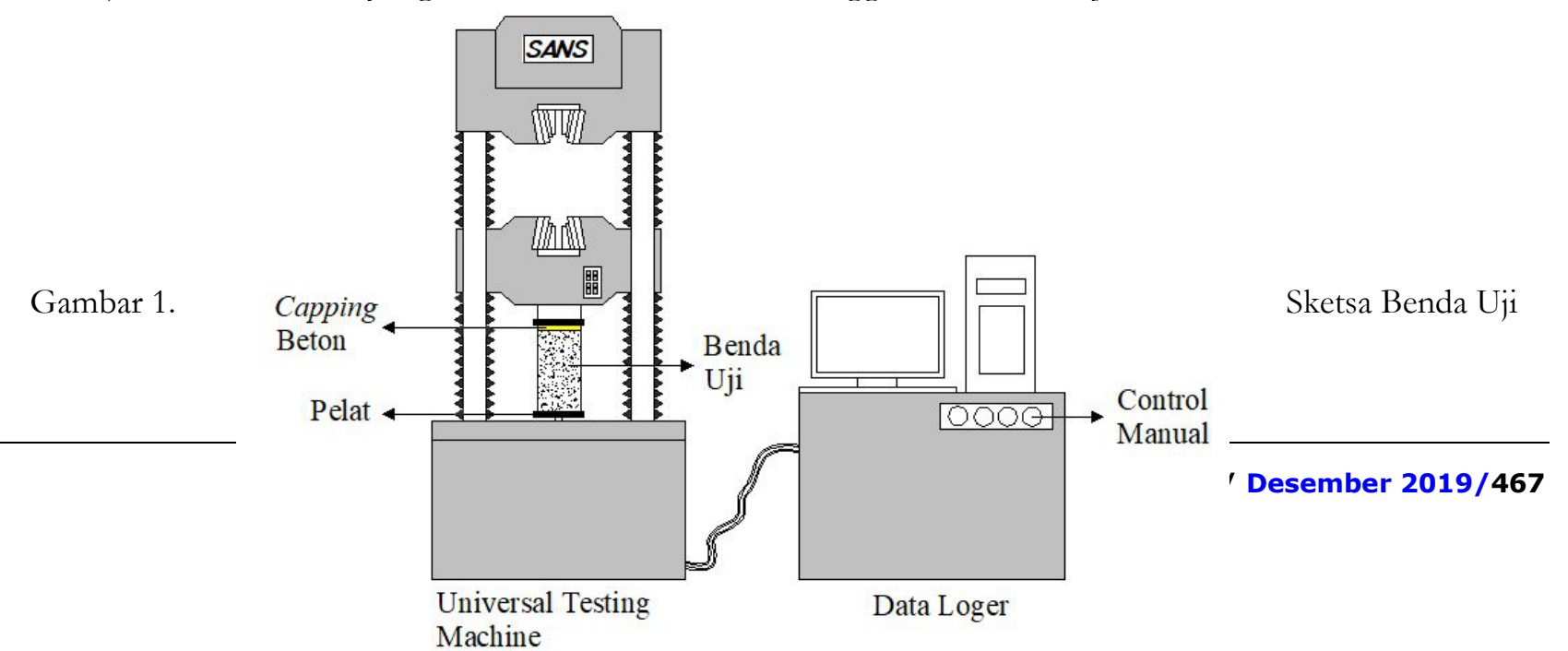


Gambar 2. Setting Up Pengujian

\section{HASIL DAN PEMBAHASAN}

\section{Hasil Pengujian Material}

Pengujian terhadap agregat kasar meliputi pengujian berat jenis (specific gravity), gradasi agregat kasar, dan keausan (abrasi). Hasil pengujian tersebut disajikan dalam Tabel 1 sebagai berikut:

Tabel 1. Hasil Pengujian Agregat Kasar

\begin{tabular}{clccc}
\hline No. & \multicolumn{1}{c}{ Jenis Pengujian } & Hasil Pengujian & Standar & Kesimpulan \\
\hline 1 & Bulk Specific Gravity & $2,51 \mathrm{gr} / \mathrm{cm}^{3}$ & - & - \\
\hline 2 & Bulk Specific SSD & $2,56 \mathrm{gr} / \mathrm{cm}^{3}$ & $2,5-2,7 \mathrm{gr} / \mathrm{cm}^{3}$ & Memenuhi syarat \\
\hline 3 & Apparent Specific Gravity & $2,65 \mathrm{gr} / \mathrm{cm}^{3}$ & - & - \\
\hline 4 & Absorbtion & $2,10 \%$ & - & - \\
\hline 5 & Keausan Agregat & $26,92 \%$ & $<50 \%$ & Memenuhi syarat \\
\hline
\end{tabular}

Pengujian terhadap agregat halus meliputi pengujian berat jenis (specific gravity), gradasi agregat, dan kandungan lumpur yang terkandung pada agregat halus. Hasil pengujian tersebut disajikan dalam Tabel 2 sebagai berikut:

Tabel 2. Hasil Pengujian Agregat Halus

\begin{tabular}{clccc}
\hline No. & \multicolumn{1}{c}{ Jenis Pengujian } & Hasil Pengujian & Standar & Kesimpulan \\
\hline 1 & Bulk Specific Gravity & $2,50 \mathrm{gr} / \mathrm{cm}^{3}$ & - & - \\
\hline 2 & Bulk Specific SSD & $2,55 \mathrm{gr} / \mathrm{cm}^{3}$ & $2,5-2,7 \mathrm{gr} / \mathrm{cm}^{3}$ & Memenuhi syarat \\
\hline 3 & Apparent Specific Gravity & $2,63 \mathrm{gr} / \mathrm{cm}^{3}$ & - & - \\
\hline 4 & Absorbtion & $1,94 \%$ & - & - \\
\hline 5 & Kandungan Lumpur & $4,50 \%$ & Maksimal $5 \%$ & Memenuhi syarat \\
\hline 6 & Kandungan Zat Organik & Kuning Muda & Kuning Muda & Memenuhi syarat \\
\hline
\end{tabular}

Pengujian fly ash yang didapatkan berupa hasil jumlah kandungan $\mathrm{Al}_{2} \mathrm{O}_{3}+\mathrm{SiO}_{2}+\mathrm{Fe}_{2} \mathrm{O}_{3}$ sebesar $64,17 \%$ dengan kandungan $\mathrm{Al}_{2} \mathrm{O}_{3}$ sebesar $11,29 \%, \mathrm{SiO}_{2}$ sebesar 31,76 \%, $\mathrm{Fe}_{2} \mathrm{O}_{3}$ sebesar 21,12\%. Sedangkan kadar $\mathrm{SO}_{3}$ sebesar 1,67\% dan $\mathrm{CaO}$ sebesar 15,02 \%. Sehingga menurut ASTM C-618 fly ash yang digunakan termasuk kedalam fly ash kelas C sedangkan menurut CSA A3001 termasuk fly ash tipe $\mathrm{Cl}$.

\section{Rancang Campur (Mix Design)}

Rancang campur yang dibuat untuk kebutuhan bahan beton jenis HVFA-SCC (High Volume Fly ash - Self Compacting Concrete) dan jenis beton normal dalam $1 \mathrm{~m}^{3}$ disajikan dalam Tabel 3 sebagai berikut:

Tabel 3. Mix Design Beton HVFA-SCC (High Volume Fly ash - Self Compacting Concrete) dan Beton Normal

\begin{tabular}{lccccccc}
\hline Kode & $\begin{array}{c}\text { Presentase } \\
\text { Fly ash }\end{array}$ & $\begin{array}{c}\text { Semen } \\
\left(\mathbf{k g} / \mathbf{m}^{3}\right)\end{array}$ & $\begin{array}{c}\text { Fly ash } \\
\left(\mathbf{k g} / \mathbf{m}^{3}\right)\end{array}$ & $\begin{array}{c}\text { Kerikil } \\
\left(\mathbf{k g} / \mathbf{m}^{3}\right)\end{array}$ & $\begin{array}{c}\text { Pasir } \\
\left(\mathbf{k g} / \mathbf{m}^{3}\right)\end{array}$ & $\begin{array}{c}\text { Air } \\
\left(\mathbf{l t} / \mathbf{m}^{3}\right)\end{array}$ & $\begin{array}{c}\text { Sp } \\
\left(\mathbf{l t} / \mathbf{m}^{3}\right)\end{array}$ \\
\hline HVFA-SCC & $50 \%$ & 250 & 250 & 773,70 & 870,30 & 145 & 8 \\
\hline NC & - & 450 & - & 954,69 & 670,31 & 225 & - \\
\hline
\end{tabular}

Hasil Pengujian Beton Segar 
Hasil pengujian dari beton HVFA-SCC (High Volume Fly ash - Self Compacting Concrete) terdiri dari Flow Table Test, $L$-Box Test, dan $V$-funnel Test, sedangkan beton normal dilakukan pengujian slump. Hasil pengujian tersebut disajikan dalam Tabel 4 sebagai berikut :

Tabel 4. Hasil Pengujian Beton Segar HVFA-SCC (High Volume Fly ash - Self Compacting Concrete)

\begin{tabular}{lcccc}
\hline $\begin{array}{c}\text { Jenis } \\
\text { Pengujian }\end{array}$ & Parameter & $\begin{array}{c}\text { Hasil Pengujian Beton Segar } \\
\text { Kadar } \boldsymbol{F l y} \text { ash } \mathbf{5 0 \%}\end{array}$ & $\begin{array}{c}\text { Persyaratan Beton SCC } \\
\text { (EFNARC 2002) }\end{array}$ & Kesimpulan \\
\hline \multirow{2}{*}{ Flow Table Test } & Diameter $(\mathrm{mm})$ & 700 & $600-700 \mathrm{~mm}$ & Memenuhi syarat \\
\cline { 2 - 5 } & $\mathrm{t} 50(\mathrm{detik})$ & 3,16 & $2-5$ detik & Memenuhi syarat \\
\hline L-Box Test & $\mathrm{h} 1 / \mathrm{h} 2$ & 0,94 & $0,8-1$ & Memenuhi syarat \\
\hline L-Box Test & $\mathrm{t}(\mathrm{detik})$ & 9,34 & $8-12$ detik & Memenuhi syarat \\
\hline
\end{tabular}

Hasil pengujian dari beton normal didapatkan nilai slump sebesar $11 \mathrm{~cm}$.

\section{Kuat Tekan}

Hasil dari nilai kuat tekan yang didapatkan dari pengujian benda uji pada alat UTM (Universal Testing Machine) bertujuan untuk mengetahui grafik hubungan antara tegangan - regangan beton yang terjadi saat pembebanan tertentu sampai mengalami keruntuhan. Data hasil kuat tekan pada beton HFVA-SCC dan beton normal disajikan pada Tabel 5 sebagai berikut :

Tabel 5. Hasil Pengujian Kuat Tekan Beton HVFA-SCC dan Beton Normal

\begin{tabular}{ccc}
\hline \multirow{2}{*}{ Parameter } & \multicolumn{2}{c}{ Benda Uji } \\
\cline { 2 - 3 } & Beton HVFA-SCC & Beton Normal \\
\hline Kuat Tekan $(\mathrm{MPa})$ & 38,95 & 34,88 \\
\hline
\end{tabular}

Hasil Grafik Hubungan Tegangan-Regangan Beton

Data - data yang diambil pada pengujian kuat tekan meliputi data pembebanan dan perubahan panjang yang diperoleh dari pembacaan alat UTM (Universal Testing Machine) dan di plot menggunakan microsoft excel menjadi grafik hubungan tegangan dengan regangan rata-rata seperti dibawah.

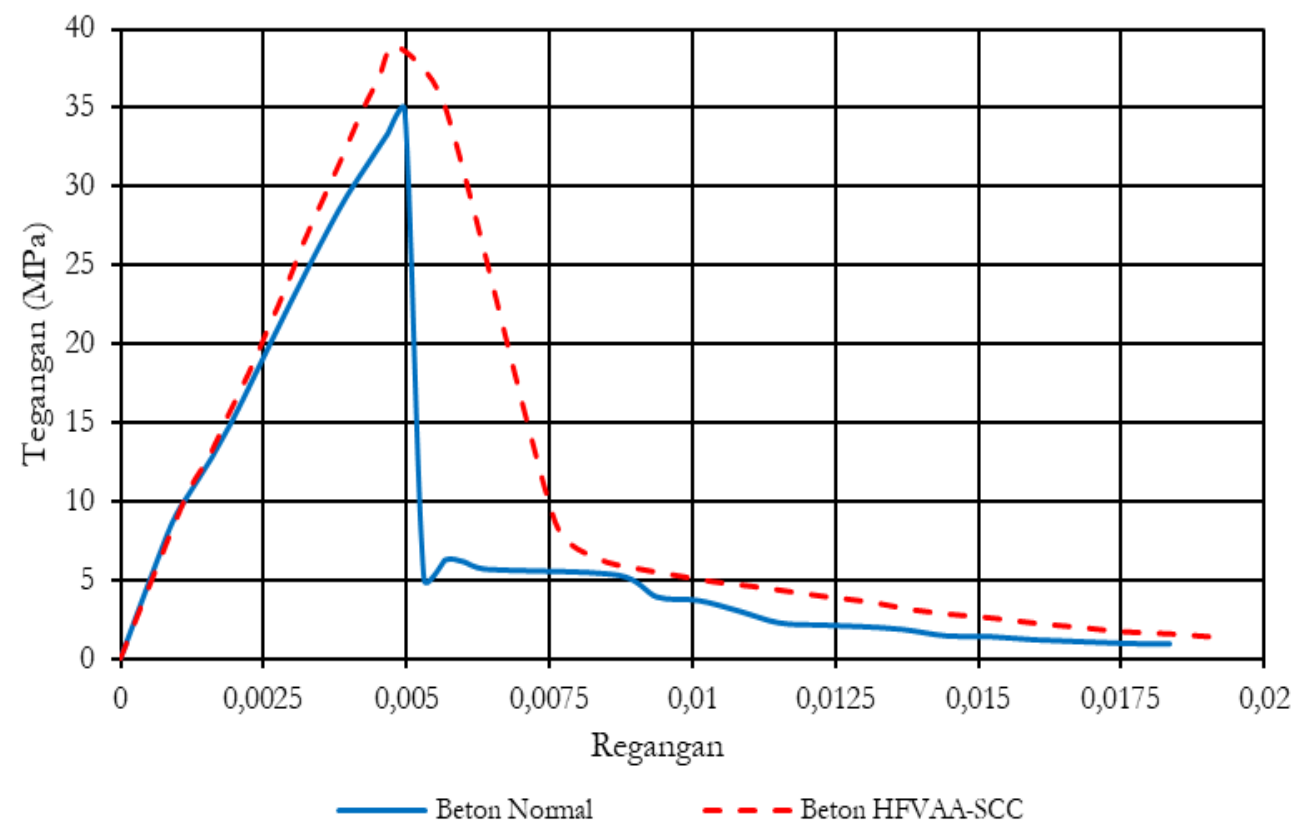

Gambar 3. Grafik Tegangan - Regangan Beton HVFA-SCC dan Beton Normal

Berdasarkan Gambar 3, didapatkan nilai tegangan maksimum (Maximum Stress) sebesar 38,95 MPa pada beton HVFA-SCC dan 34,88 MPa pada beton normal. Nilai regangan pada saat tegangan maksimum (peak strain) sebesar 0,00483 pada beton HFVA-SCC dan 0,00497 pada beton normal. Dapat diketahui bahwa penambahan fly ash pada penelitian ini dapat mempengaruhi penambahan nilai kuat tekan pada beton. Nilai dari tegangan dan regangan beton disajikan pada Tabel 6 sebagai berikut : 
Tabel 6. Hasil Pengujian Tegangan dan Regangan Beton HVFA-SCC dan Beton Normal

\begin{tabular}{lcc}
\hline \multirow{2}{*}{ Parameter } & \multicolumn{2}{c}{ Benda Uji } \\
\cline { 2 - 3 } & Beton HVFA-SCC & Beton Normal \\
\hline Maximum Stress $(\mathrm{MPa})$ & 38,95 & 34,88 \\
\hline Peak strain $\left(\boldsymbol{\varepsilon}_{0}\right)$ & 0,00483 & 0,00497 \\
\hline
\end{tabular}

\section{SIMPULAN}

Dari pembahasan diatas dapat disimpulkan sebagai berikut:

1. Penambahan fly ash pada beton HVFA-SCC (High Volume Fly ash - Self Compacting Concrete) dengan kadar fly ash 50\% dengan umur beton 28 hari memiliki nilai kuat tekan yang lebih besar dari pada beton normal, artinya penambahan fly ash dapat menambah kekuatan pada beton.

2. Nilai regangan pada saat tegangan maksimum (peak strain) yang terjadi antara beton HVFA-SCC (High Volume Fly ash - Self Compacting Concrete) dengan beton normal memiliki nilai yang sama yaitu berkisar antara $0,004-0,005$.

\section{UCAPAN TERIMAKASIH}

Ucapan terima kasih penulis sampaikan kepada Agus Setiya Budi, S.T., M.T. dan Dr. Endah Safitri, S.T., M.T. selaku pembimbing yang dengan penuh kesabaran dan keikhlasan telah memberi koreksi dan arahan sehingga menyempurnakan hasil karya tulis penyusunan. Rasa terima kasih penulis sampaikan juga kepada tim skripsi Gabungan Super yang telah berjuang bersama untuk menggapai kelulusan.

\section{REFERENSI}

Andreas Nur Hadi. 2017. "Pengarub Kadar Fly ash Terbadap Hubungan Tegangan dan Regangan pada High Volume Fly ash Self Compacting”, Skripsi, Program Studi Teknik Sipil Universitas Sebelas Maret. Surakarta.

Anonim. 2002. "The European Guidelines for Self-Compacting Concrete Specification, Production and Use". The European Federation of Specialist Construction Chemicals and Concrete Systems (EFNARC).

Anonim. 2003. "Standard specification for fly ash and raw calcined natural pozzolan for use as mineral admixture in portland cement concrete (ASTM C 618-03 2003)". Philadelphia, United States: Annual Book of ASTM Standard.

Anonim. 2005. "The European Guidelines for Self-Compacting Concrete Specification, Production and Use". The European Federation of Specialist Construction Chemicals and Concrete Systems (EFNARC).

ASTM, C. 2001. "Standard test method for density, relative density (specific gravity), and absorption of fine aggregate". United States: ASTM International.

ASTM, C. 2002. “, Standard Test Method for Sieve Analysis of Fine and Coarse Aggregates". Annual Book of Standards, 4(02). ASTM

C. 2003."Standard Test Method for Materials Finer than 75-um (No. 200) Sieve in Mineral Aggregates by Washing". Anl/llal Book ofIISTM S/(//](Iards, 4).

ASTM, C. 2014. 1611. "Standard test method for slump flow of self-consolidating concrete", ASTM Int, 1-6.

Karina Puspa Amalia. 2018. "Pengaruh Kadar Fly ash Terbadap Karakteristik. Material Pada High Volume Fly ash Self Compacting Concrete (HVFA-SCC)”, Skripsi, Program Studi Teknik Sipil Universitas Sebelas Maret. Surakarta.

Kumar Mehta. 2006. High Volume Fly ash Concrete for Sustainable Development. International Workshop on Sustainable Development and Concrete Technology. University of California.USA. 